24 and 27 years, and the third was a young lady aged 23 years. In all three cases the adrenalin was given internally in doses of five minims of solution adrenalin chloride (Takamine) 1 in 1000 in a teaspoonful of water three times daily half an hour before food. The remedy was continued during five to six months, with short intervals of one or two weeks, and had a remarkable effect on the erythema, which almost entirely disappeared. Up to now, a year and a half after treatment, the redness has not reappeared, and no bad effect on the heart or blood pressure has been observed.

I am, Sir, yours faithfully,

Kharkoff, Jan. 1st, 1909

Dr. Med. E. A. Rothmanr.

\section{THE ETIOLOGY OF CARCINOMA CERVICIS.}

\section{To the Editor of THE LANCET.}

SIR,--In your annotation in The LANCET of Jan. 9th referring to my paper read at the Harveian Society on Dec. 10th it is stated that Dr. Comyns Berkeley and I had performed 20 radical abdominal operations (Wertheim) for carcinoma of the cervix with four deaths. This is incorrect. Up to the reading of that paper we had performed 28 of these operations with four deaths. Will you kindly publish this correction? Very faithfully yours,

Harley-street, W., Jan. 9th, 1909. VICTOR BONNEY.

** We have pleasure in publishing the correction.ED. L.

\section{"AN INDEX OF TREATMENT."}

\section{To the Editor of THE LANCET.}

SIR,-We thank you for the appreciative notice of the above volume in your issue of this date. We feel, however, that when you say "we should hardly have thought that keeping the book up to date by frequent issues would have necessitated four editions within 12 months," and further suggest that "a better plan in future would be to print an edition large enough for requirements not more than once a year," some readers will infer that we purposely sent out small issues with a view to multiplied editions. This touches us on a tender spot. We may not be leaders amongst medical publishers, but we have always most distinctly set our faces against what is a crying evil of today (though, we are glad to think, less prevalent among British than some foreign houses) of issuing what are known as "faked" editions of works with fresh title-pages but no true claim to be new editions, the object being obviously to create a false impression.

This is not so in our case. Each edition of the "Index," it was thought, would be sufficient for about 18 months' demand. In order, however, to be perfectly clear may we state that the first edition consisted of 2500 copies plus 1500 for America revised in dosage by the U.S.A. Pharmacopoeia, the second and third editions 1000 copies each, while the fourth and present issue is 2000 copies, of which at the moment of writing about half have been disposed of.

If you can kindly find room for this explanation we think it will clear us from any unjust suspicion of lack of straight dealing. It seems only fair to editors and contributors alike to make it understood that the appearance of so many impressions in so brief a period is solely because up to now the demand for this volume has exceeded the anticipation we had any of us formed of it.

We remain, Sir, yours faithfully,

Bristol, Jan. 9th, 1909. JOHN WRIGHT AND SoNs, LTD.

Royal Medical Society of Edinburgh.-At a meeting of this society held on Jan. 8th, Dr. A. C. B. McMurtrie read a paper on Hæmaturia. At the outset he tonched upon hæmoglobinuria, relating the conditions under which blood pigment might be found in the urine. Passing on to hæmaturia proper Dr. McMurtrie gave a very clear and complete account of all the conditions affecting the genito-urinary tract which might be associated with the presence of blood in the urine. In some of these hæmaturia was present almost as a rule; in others it was a comparatively rare occurrence.

\section{RECONSTRUCTION OF THE GLASGOW ROYAL INFIRMARY. \\ (FROM A CORRESPONDENT.)}

THE scheme for the reconstruction of the Royal Infirmary has been before the public for nearly ten years and it seems as if now it were fairly under way, as one of the ward blocks is nearing completion and the north half of the gatehouse or admission block will be ready for occupation in a few months. The reconstruction when complete will involve a total expenditure of $£ 500,000$ and the new infirmary will accommodate 660 patients.

Before commencing building operations the managers of the infirmary remitted the plans to hospital experts, as is now usually the custom, with a view of getting any suggestions which they might think advisable for the improvement of the plans in detail or as a working whole. The experts chosen in this case were Sir Henry C. Burdett, K.C.B. K.C.V.O., and Dr. Donald J. Mackintosh, M.V.O. The plans as modified by them represent a modern up-to-date hospital and contain certain novel features of interest. It must be recollected that both the architects and the experts have been hampered to a certain extent by the fact that the new buildings have to be erected on the site of the old hospital, which is somewhat restricted in area, but notwithstanding that it is evident from a perusal of the plans now issued that the isolation for the different sets of wards has. been most satisfactorily accomplished, and the fullest hygienic advantages as regards light and air have been attained.

All accident cases and patients seeking admission to the infirmary will enter by the central gatehouse in Castle-street. On the left is placed the porters' room where applicants will be met by one of the porters. Thence the patients are conducted to a central hall with examination and dressing rooms for males and females on each side. At the end of the central hall are placed an operation theatre for female casualties with a recovery room adjoining, and on the right hand an operation theatre for males, while between the two theatres are rooms for sterilisers and dressings. There is an $x$ ray examination room close at hand. In the basement are bathrooms for bathing the patients. To explain the working of these arrangements, it may be pointed out that the patient, when found to be a case for admission, is taken on a lift to the floor below, and if not too ill is bathed and has his clothes stored in the basement. From here, wrapped in a dressing-gown and blankets, he is taken in an ambulance by a well-heated underground passage to one of the wards. On the right side of the gatehouse block special arrangement is made for noisy and emergency cases. A ward of four beds and two single wards are provided for males and a similar number for females. These wards have double doors and double windows, so that no noise can be heard in the hospital or street.

Coming to the hospital proper, which is situated behind and at some distance from the gatehouse, the whole arrangement of the basement is planned in such a way as to provide in the simplest and readiest manner for the efficient administration of the various departments and the easy working of the entire hospital. Here is accommodation for stores and linen room staff. Also the porters' and wardmaids' diningrooms, with ample accommodation for the dispensing department, including a fireproof store for inflammables. Above the basement the building rises for six storeys and is, roughly speaking, divided into three great blocks completely cut off from one another by cross ventilating passages. In addition, the separate ward units are cut off from one another by similar passages.

To take a general view, the left block rising stage above stage to the sixth floor is devoted to surgical wards with a theatre attached on each floor. Without seeing the plans it is difficult to imagine how admirably the separate wards and theatres have been isolated from the other buildings and from one another, being connected only by communicating freely ventilated corridors and thereby insuring the maximum of light and air. The medical wards comprised in the block on the right hand are arranged in much the same manner, with the exception that on the ground floor the space is mainly occupied by the electrical department. The central block is situated between the two blocks already described 